kazalište, osobito kad govori o najtežim temama društvene savjesti kao što to čini primjerice ZKM-ov Eichmann $u$ feruzalemu. U prethodnoj knjizi (U san nije vjerovati) autorica je spomenula kako su izvedbeni studiji, militantno-optimistički i edukativno-pedagoški ustrojeni, Goffmana potisnuli iz svog disciplinarnog mainstreama zbog njegove analitičke distance i emocionalnog odmaka. Slično svojim misaonim sugovornicima i srodnicima i Čale Feldman promatra umjetničku produkciju, političku pozornicu i karnevalsku svakodnevicu iz dubine gledališta, kao višestruko kodiranu predstavu. Za čitavo naše humanističko, a rekla bih i društveno polje, njezina je pozicija moćan podsjetnik na to kako tumačenje umjetnosti može imati jači učinak od pukog govora o stvarnosti.

Natka Badurina

\section{DISKURZIVNI POVRATAK SUBJEKTA}

Varja Balžalorsky Antić, Lirski subjekt: rekonceptualizacija. Ljubljana: ZRC SAZU, Inštitut za slovensko literaturo in literarne vede. 2019. 304 str.

Književnost našeg doba, obeleženog socijalnim, kulturnim, komunikacijskim i medijskim fenomenima bez pandana $\mathrm{u}$ prošlosti, zainteresovanim proučavaocima ispostavlja ceo niz paradoksa. Jedan od najizrazitijih predstavlja činjenica da je pesnička produkcija dostigla nezapamćene razmere, ali je, s druge strane, zanimanje izdavača i publike za ovaj vid literarnog umeća možda i manje nego ikada pre. U takvoj situaciji teorijsko i interpretativno-kritičko bavljenje poezijom ukazuje se gotovo kao kulturni incident i presedan svoje vrste. U prilog ovoj konstataciji govori čak i ovlašan uvid u produkciju tzv. diskurzivne literature, koja je još mnogo ređa od pesničke. Baš zbog toga je, čini se, još značajnija pojava svakog ozbiljnog pokušaja bavljenja pesništvom i svim onim što je povezano s njegovim bitnim odlikama.

Prva naučna monografija Varje Balžalorsky Antić čitaocu nudi upravo to - metodično i akribično iznetu primenu savremenih shvatanja jezika i književnosti $\mathrm{u}$ oblasti teorije lirike i njoj svojstvene problematike. Kao što je razaznatljivo već iz naslova, ova intrigantna i podsticajna studija, prva takve vrste na slovenačkoj, ali i regionalnoj sceni, rezultat je ambicije da se poimanje subjekta, već stolećima središnje instance lirskog pesništva, postavi na osnove primerene aktuelnim dostignućima književnonaučne, lingvističke, ali isto tako i filozofske misli kao onog područja iz kojeg je ovaj pojam izvorno i potekao.

Gradeći teorijsku platformu za svoj pristup, Varja Balžalorsky Antić polazi od konstatacije da je takozvana smrt 
subjekta, oglašena u strukturalističkim i poststrukturalističkim teorijama prošlog stoleća, na izvestan način stavljena ad akta i da se famozni nosilac mišljenja, delanja i/ili pevanja vraća u fokus naučnog razmišljanja i raspravljanja. Stolećima posmatran u zadatom okviru generalnog shvatanja što bi se moglo označiti kao esencijalistička iluzija o (meta)fizičkoj opstojnosti, koju su podržavali filozofsko, teološko, a onda i estetičko mišljenje, subjekat se sada u teorijskim shvatanjima razume najvećma antiesencijalistički, kao dinamičan kulturni fenomen i epistemološki konstrukt, primeren ukupnoj mentalnoj, intelektualnoj i estetskoj koordinaciji našeg doba.

Zahvaljujući romantičarskoj ideji samoizražavanja (Selbstaussprache), a potom i pozitivističkoj doktrini empirijske determinisanosti (sa)znanja, u nauci o književnosti, i posebno u teoriji lirskog pesništva, na pragu modernog doba pomenuta esencijalistička iluzija dobila je dalekosežno uticajne vidove ispoljavanja koji su za dugo vreme odredili poimanje subjektivnosti što je bilo omeđeno "unutarnjim" i "spoljnim" činiocima pretpostavljene personalnosti, sopstvenosti itd. Autorka Teorije lirskog subjekta podseća, međutim, na to da je prevratnička epoha idealizma i romantizma ponudila i drugačije mogućnosti poimanja subjekta i njegovih estetskih, artističkih i jezičkih manifestacija. Tražeći način za prevladavanje parcijalnog pristupa fenomenu, Varja Balžalorsky Antić zato reafirmiše shvatanje Fridriha Šlajermahera, oca moderne hermeneutike, o tome da se individualni stil realizuje u jeziku kao nadindividualnoj, intersubjektivnoj kategoriji, ali da je jezik zapravo delanje i činjenje, a ne puki niz znakova i njihovih relacija, pa stoga u umetničkoj upotrebi svaki put predstavlja osobenu, neponovljivo ustrojenu konstelaciju.
Stoga ne treba da iznenadi što se potpisnica ovog pomno obrazloženog predloga za rekonceptualizaciju, a to znači za ponovno fundiranje pojma lirskog subjekta, u daljoj elaboraciji u mnogo čemu naslanja i na teorijska stanovišta Emila Benvenista, jednog od najuticajnijih lingvista dvadesetog veka, koji je poput Šlajermahera i sam zastupao aktivističko shvatanje jezika. Kod Benvenista je pri tome težište na subjektivizaciji kao temeljnoj odrednici neposredne upotrebe jezika, koju, po francuskom jezikoslovcu, valja razumeti kao naročito psihičko jedinstvo ili celovitost što nastaje u samom govoru/kazivanju. Poznato Benvenistovo stanovište da jezik postoji u dva vida, kao langue i kao parole, te da je Ja onaj ko govori, nezavisno od njegove ekstralingvističke legitimacije, veli Varja Balžalorsky Antić, zapravo otvara put savremenim teorijama diskursa kao svojevrsnog dogadanja u jeziku.

Stavljanje diskursa i njegovog događajnog dejstva u prvi plan teorijskog razumevanja otvara put prevlasti neegološkog i neesencijalističkog shvatanja subjekta kao energio, kao diskurzivno delatne instance. Zato Benvenistova stanovišta u ovoj studiji najbliže rezonuju s teorijskim uvidima Mihaila Bahtina o imanentno dijaloškoj prirodi diskurzivne aktivnosti u polju estetskih tvorevina, u prvom redu književnih. Ukazujući i na neke protivrečnosti u shvatanjima ruskog teoretičara, prvenstveno na njegovo poimanje lirike kao bitno monološkog diskursa, Varja Balžalorsky Antić snažno reafirmiše Bahtinovo stanovište o relaciono-dijaloškom ustrojstvu subjektivnosti koje se najjasnije manifestuje upravo u artističkoj ekspresiji. Valja dodati da bi tako postavljenom izlaganju od pomoći bila i Bahtinova teorija govornih žanrova, kao i još neke teorijske platforme iste ili slične orijentacije, poput široko primen- 
ljivog koncepta interdiskurzivnosti kao savremenog odgovora na izazove koje je filozofiji, lingvistici i drugim disciplinama ispostavila post-epoha rastvaranja (meta)stabilnih struktura i konstelacija. ${ }^{1}$

Eksplicirajući odabrani pristup Varja Balžalorsky Antić daje sistematičan pregled teorijskih gledanja na estetski shvaćen koncept subjekta, počev od Hegela, Šelinga, Novalisa i Ničea, preko Sartra, Emila Štajgera, Pola Rikera, Entonija Isthoupa i Karlhajnca Štirlea, pa do Manfreda Franka, Julije Kristeve, Janka Kosa i drugih. Pokazujući izrazitu sposobnost razlikovanja teorijski produktivnih i neproduktivnih stanovišta i u okviru jednog istog doprinosa, autorka Lirskog subjekta katkad ima i polemički pristup, na primer u pokušaju revizije pretežno kritizerskog gledanja na "logičku" teoriju pesništva Kete Hamburger. U samo središte svoje diskurzivne paradigme na ovaj fenomen Balžalorsky Antić smešta shvatanja Anrija Mešonika (Henry Meschonnic), kod nas manje poznatog francuskog teoretičara koji posebnu pažnju poklanja upravo problemima neposredne pesničke upotrebe jezika (Pour la poétique, 1970; Le Signe et le poème, 1975; Critique du rythme, 1982; États de la poétique, 1985; La rime at la vie, 2006). Ono što Mešonika čini povlašcenim jeste njegova platforma "poetike

${ }^{1}$ Isto važi i za teoriju subjekta Petera Zime, recimo. Uz rezonovan pregled relevantnih (post)modernih shvatanja subjekta, u kojem baš Bahtinove teze imaju značajno mesto, austrijski filozof u svojoj instruktivnoj Theorie des Subjekts (2000) iznosi, naime, i sopstvenu teorijsku platformu za dijaloško razumevanje subjekta. Zanimljivo je da se i tu, kao i u Lirskom subjektu, referira na funkcije refleksivnosti i narativnosti kao posebno značajne u procesu konstituisanja subjektivne instance. diskursa" koja zahvaljujući insistiranju na istoričnosti i političnosti jezika/govora korespondira sa savremenim transdisciplinarnim teorijama kulture i tzv. teorijom svega (théorie de l'ensemble).

Svojim razumevanjem pesničkog diskursa Mešonik se transparentno pridružuje onim pristupima koji se zasnivaju na kritici statično shvaćene sosirovske lingvistike u korist ideje procesualnosti, otvorenosti, nedovršivosti i singularno pojmljene jezičke i/ili tekstualne sistematičnosti što proizlazi iz orijentacije na artistički “živ", neposredno delatan i performativno "proizvodeći”, estetski funkcionalan jezik. U tom smislu Varja Balžalorsky Antić kao najznačajniji momenat Mešonikove "poetike diskursa" afirmiše primat subjekta konkretnog iskazivanja (énonciation) naspram apstrahovanog subjekta iskaza (énoncé) kao takvog. To znači da se famozni lirski subjekat teorijske tradicije sklanja u stranu, a u prvi plan stupa subjekat pesme kao jedinstven i neponovljiv, diskurzivno generisan fenomen, u svakom pojedinom lirskom činu podložan autonomnim funkcijama i odgovarajućim semantičkim, odnosno smislotvornim reperkusijama.

Možda i ključni momenat Mešonikovog teorijskog doprinosa predstavlja zamisao o neunitarnosti subjekta u značenju tradicijski shvaćenog i povlašćenog cogita. On sada postaje polje dijalektičkog ukrštanja predrefleksije i refleksije, iracionalno-intuitivnih i racionalno-inteligibilnih dejstava u uvek transformativnom procesu (samo)artikulacije, u kojem subjekat kao energio oblikuje diskurs, ali i diskurs takođe bitno utiče na njegovo vlastito, dinamično uprizoreno i kompleksno "obličje". Poklanjajući posebnu pažnju često zapostavljanim, predrefleksijskim aspektima lirske subjektivnosti, Anri Mešonik pri tome stavlja težište na ono što skupno imenuje kao "recitativ", 
a što podrazumeva čulno-materijalnu dimenziju pevanja, pre svega ritam kao temeljni antropološko-ekspresivni momenat poetskog diskursa, kao autentičan momenat konfiguracije celine pesme, a ne tek kao formalnu potkategoriju. Varja Balžalorsky Antić sasvim razložno insistira upravo na mešonikovski shvaćenim recitativno-ritamskim sredstvima kao artikulacijskom poligonu poetske subjektivnosti. Nije naodmet pomenuti da se ovakvo shvatanje zapravo nadovezuje na tendenciju koja je primetna u relativno retkim, ali utoliko značajnijim novijim pokušajima vraćanja teorije pesništva na izvorne, u mnogo čemu distinktivne značajke lirskog žanra (npr. H. Schlaffer, Geistersprache, 2012; J. Culler, Theory of the Lyric, 2015). ${ }^{2}$

Valja, s druge strane, podsetiti i na ikonički aspekt lirske individuacije, kao

182 što to, recimo, čini Nortrop Fraj u proslavljenoj Anatomy of Criticism (1957), u kojoj uz melos ("musical", "sound patterning") figurira i opsis ("pictorial", "visual construction"), posebno važan u modernom i savremenom pesništvu, u velikoj meri lišenom konvencionalnih

${ }^{2} \mathrm{U}$ tom kontekstu instruktivnim se čini uočavanje da bitna obeležja Kalerovog pristupa - najavljena, čini se, već eksplikativnim tretmanom pesničke problematike i gramatike književnosti u uticajnoj Structuralist Poetics (1975) - pokazuju izvesnu sličnost sa Mešonikovom koncepcijom, budući da se knjiga američkog teoretičara otvara analizama devet pesama kao konkretnim predloškom za teorijsku artikulaciju što sledi, u okviru koje pak istaknuto mesto zauzimaju metar, ritam i ponavljanje, tj. recitativni elementi lirske strukture. Nešto slično moglo bi da se kaže i za studiju Hajnca Šlafera koja, reafirmišući izvorne kvalitete lirskog modusa, i sama poklanja dosta pažnje njegovim recitativnim aspektima. formalno-konstruktivnih činilaca (metar, prozodija, rima itd) u korist slobodnog stiha i njemu primerenih, vizuelno $\mathrm{i} / \mathrm{ili}$ grafički uprizorujućih potencijala pevanja (konkretistička, kaligramska poezija i sl). Stoga bi, čini se, u daljoj teorijskoj elaboraciji i ovaj aspekt valjalo relacionirati prema diskurzivno-procesualno shvaćenoj instanci lirske subjektivnosti.

Pristupajući studijama slučaja koje interpretativno uprizoruju ovako postavljeno shvatanje uvek iznova samoprodukujuće subjektivnosti u pesmi, autorka odabira dva povesno udaljena primera - trubadursko pesništvo i poeziju Anri Mišoa. Reč je o oprečnim "slučajevima": trubadurska lirika je tradicijski kanonizovan i uglavnom konvencionalno čitan pesnički opus, a Mišoovo delo, iz kojega je za ovu priliku uzeta duga pesma u prozi "Usporena" ("La Ralentie"), i dalje važi kao primer nesporno antitradicionalističke, nekonvencionalne lirske pustolovine.

Pokazujući da diskurzivno shvaćena formula subjektivnosti važi i u ovako različitim slučajevima, Varja Balžalorsky Antić zapravo demonstrira njenu teorijski univerzalnu primenljivost. Pri tome je ispoljeno zavidno umeće eksplikacije osnovnih pretpostavki na konkretnom poetskom materijalu. Trubadurska poezija lišena je biografske aure, koju je dugo imala, u korist raspoznavanja retorskih opštih mesta i, posebno, rudimentarnog "višeglasja" subjek(a)ta iskazivanja kao svojevrsnog "rascepa" konvencionalne trubadurske persone na figuru (auto) refleksivnog pesnika i figuru kurtoaznog ljubavnika. Ritmičko-melodijska i akcentuacijsko-prozodijska orkestracija ovde ilustruje Mešonikovo shvatanje značaja recitativnih momenata u oblikovanju lirske subjektivnosti, što se odnosi i na Mišoovu uzornu pesmu u prozi, koja se takođe "razlistava" na nikad do kraja 
diferencirane glasove, a uz to upravo uz pomoć dejstva formalno-konstruktivnih sredstava sugeriše ono što autorka imenuje kao "radikalnu subjekatsku fluidnost" u lirici francuskog pesnika.

Ovako uobličena (re)koncepcija subjekta pesme kao uvek dinamične i singularne, a ne unitarno-apstraktne konstrukcije diskurzivnih prosedea koji tvore iskaznu osovinu lirskog pevanja otvara nove horizonte očekivanja. Ona, naime, podrazumeva neku vrstu sistematike, ili bar provizoran pregled teorijski plauzibilnih mogućnosti artikulacije lirske subjektivnosti. Na samom završetku svoje studije Varja Balžalorsky Antić upravo to i donosi u vidu nacrta "tipologije subjektnih središta u [lirskoj] dijegezi", na čijem početku stoji pesma bez "lika" i iluzivnog dejstva lirske "osobnosti", u centralnom delu je lepeza međumogućnosti: "monološka dijegeza s glavnom lirskom personom", bila ona subjekt iskaza ili ne (uz dalje tipološke opcije: antropomorfna, neantropomorfna, kolektivna persona itd), zatim slede različita "subjektna središta s dejstvom svetskih bića", pa elementi nežive prirode, odnosno personifikacije, alegorije i simboli s lirskom personom ili bez nje, zaključno sa "hibridnim" mogućnostima kombinacije ili preplitanja prethodno naznačenih opcija kao krajnje mogućnosti.
Pomenuta skica posledično traži, naravno, i razvijenu interpretativno-hermeneutičku elaboraciju kao neposrednu proveru njene književno-estetske funkcionalnosti. Ma koliko bili samorazumljivi ili hermetični, simplifikovani ili multiplikovani, pesnički kreirani oblici lirske subjektivnosti uvek, naime, služe estetskoj komunikaciji u smislu posredovanja kulturno deljivih značenja i njihovih konfiguracija. Onako kao što je tradicionalna, egološka koncepcija subjekta služila određenim kulturnointerpretativnim očekivanjima, tako i neegološka koncepcija zahteva sopstvenu teleološku osnovu. A to znači da bi trebalo da nam pomogne u postupku razumevanja lirskih tvorevina i njihovih konkretno doživljenih značenja u kontekstu kulturno naturalizujućih pretpostavki ovog, oglašeno posthumanističkog doba.

Inovativna studija Varje Balžalorsky Antić postavila je valjan okvir za takvo nešto. Na način koji sasvim izvesno prevazilazi lokalne i regionalne okvire - argumentovano, sugestivno i nadasve naučno aktuelno - ona konceptualizuje jedan od najbitnijih i najviše razmatranih fenomena celokupnog pesničkog umeća. Nema sumnje da je to više nego dovoljan učinak u vremenu koje nije odveć naklonjeno teoriji lirike i lirskih fenomena uopšte.

Tihomir Brajović 